\title{
Modern paradigms of Sustainable Development: Advantages and Disadvantages
}

\author{
E. Y. Dotsenko ${ }^{1}$, N. P. Ezdina ${ }^{1}, A . S h . \mathrm{Khasanova}^{1}$, and M. I. Khasanov ${ }^{2}$
}

${ }^{1}$ Associate Professor, Plekhanov Russian University of Economics

${ }^{2}$ Associate Professor, Lomonosov Moscow State University

\begin{abstract}
The article presents an analysis of theoretical approaches and mechanisms for implementing the principles of sustainable development. The authors identify and analyze the main theoretical and methodological paradigms in relation to the concept of sustainable development: anthropocentric, biospherocentric and noospheric, identify the advantages and disadvantages of their epistemological potential. The paper examines the causal relationships and dependencies between economic, environmental and social processes in the context of the anthropocentric paradigm, defines the conditions and factors of sustainable development of economic systems of market organization.
\end{abstract}

\section{Introduction}

The manifestation of the crisis phenomena in the Russian economy with the simultaneous strengthening of external threats, reflected in the form of decisions taken by a number of foreign states to ban (restrict)the import of certain types of products, and the aggravation of the problem of the depletion of natural resources have led to an increase in the importance of factors of sustainable economic growth, the implementation of which involves the development of management measures, taking into account the peculiarities of the spatial allocation of assets and the state of the economy.

Ensuring the sustainable development of socioeconomic systems is one of the most urgent problems of modern society, due to the increasing limited resources and extremely inefficient further economic growth due to extensive factors. A significant contribution to the development of the concept of sustainable development was made by S. N. Bobylev, D. H. Meadows, D. L. Meadows, J. Randers, M. Mesarovich, J. Tinbergen, and others, whose ideas were used in the preparation of the reports of the Club of Rome (the report "limits of growth"), as well as the program documents of the UN Conference on Environment and Development (Rio de Janeiro, 1992). In accordance with the basic principles of the concept of sustainable development, the concept of dynamic growth (A. Peccei), the concept of organic growth (A. King), and the concept of dynamic equilibrium (E.Pestel), etc.

The most important task of any economic system is to ensure sustainable and balanced development. For all the development of the problem of sustainability, there are still a number of unresolved issues, which is due to their dynamism and versatility.

Among the states characterized by different state of resource potential, direction and dynamics of the main macroeconomic indicators, level and quality of life of the population, there are still differences in the composition of factors of sustainable development, in the conditions of formation and implementation of appropriate strategies at the national, subnational levels and at the level of individual economic entities. In this regard, it seems necessary to adapt the strategy of sustainable development to a particular economic agent, taking into account the peculiarities of environmental factors. In developed countries, the business community has significant opportunities for implementing corporate initiatives in the field of sustainable development, which is determined by the presence of appropriate formal institutions in the form of regulatory legal acts, program documents, as well as the state of market mechanisms, high standards of economic, environmental and general culture. In low-income countries and in developing countries, where the level of basic human needs remains low, the amount of spending on building the prerequisites for sustainable development remains insignificant, while the effectiveness of social investment can be relatively high. In the states of this group, the prerequisites for the socialization and greening of economic activity at the level of the "base of the pyramid" of A. Maslow and for the formation of an extensive client base through initiatives aimed at interacting with the population are preserved. 


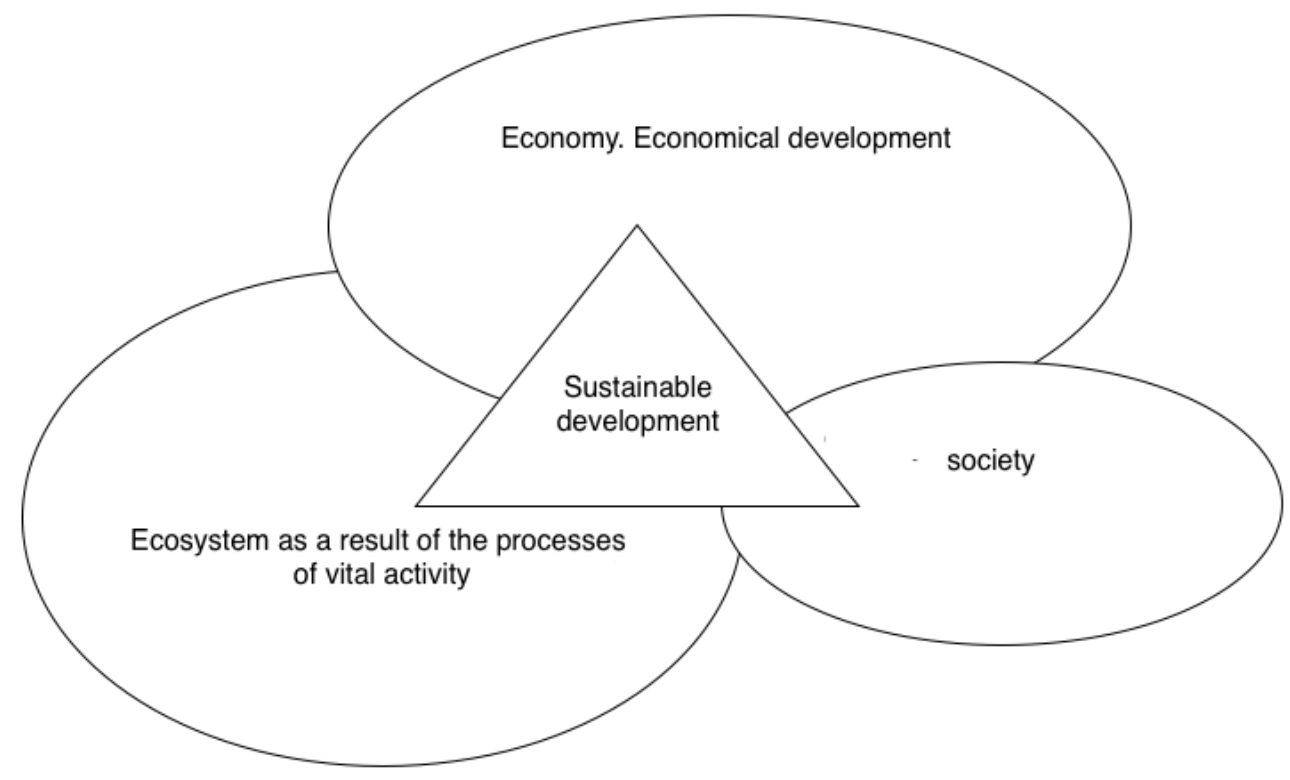

Fig. 2. General relationships between life processes and the ecosystem in the framework of the biosphere-centric paradigm.

\section{Materials and methods}

The concept of sustainable development was formed and acquired an independent theoretical status in the mid-80s of the XX century, but so far a wide range of problems has not been successfully solved.

In particular, the problem of theoretical approaches and mechanisms for implementing the principles of sustainable development remains debatable. Modern economic science distinguishes three main theoretical and methodological paradigms in relation to the concept of sustainable development: anthropocentric, biospherocentric and noospheric.

The anthropocentric (or utilitarian) paradigm was formed on the basis of the value orientations of the dominant philosophy of consumption in modern society. Modern humanity, when meeting its ever-growing needs, does not take into account the possibilities of the natural environment and the needs of subsequent generations, generates socio-ecological and economic problems, and sees the solution to the problem of the survival of modern civilization and its further development in stimulating technological progress. According to this point of view, the formation of scientific, technical and technological directions of human activity inevitably ensures sustainable development, thus, descendants will live better if previous generations leave them with advanced technical potential. However, the negative effects of scientific and technological progress on the state of the environment from the perspective of this paradigm are completely ignored.

Figure 1 shows the causal relationships between economic, environmental, and social processes within the anthropocentric paradigm.

The presented scheme shows the significance of each component of development, its dependence on the previous ones and its influence on the subsequent elements of development.

Within the framework of this paradigm, the resource approach to the consideration of problems of the development of socio-economic systems, implemented in the works of R. Solow, J. Stiglitz, J. Hartwick, T. Page, I. Y. Blam, T. Titenberg, R. K. Turner, D. Pierce, G. Atkinson, N. Georgescu-Roegen, and others, has become widespread. Ensuring the trajectory of sustainable development in the model requires replacing the consumption of non-renewable resources with anthropogenic capital, as well as a" favorable " ratio of the production elasticity of natural resources and humancreated capital. Technological progress is the only basis for sustainable growth of well-being. J. Hartwick in 1977 argued that it is necessary to invest the rental income from the exploitation of non-renewable resources in reproducible capital to maintain real consumption. None of the rental income should be consumed by the current generation. T. Page believed that the predecessors should compensate the descendants for any irrevocable reduction in resources.

The founder of the thermodynamic school, N. Georgescu-Roegen, believed that continuous economic growth is impossible due to the inevitable shortage of natural resources, the law of entropy states that a complete repeat cycle of material turnover in a closed system is impossible, so the shortage of natural resources will increase, but artificial, human, and natural capital are commensurate and interchangeable, so the sustainability of development can be achieved by reinvesting natural rent in economic capital.

Thus, the sustainable development of mankind is possible if technological progress is constantly maintained and an effective price mechanism is used, and if the current generation, existing at the expense of future generations, reduces the level of consumption. 
However, the implementation of this approach in practice is very difficult in relation to natural resources that may have use values that are not estimated by the market - biological diversity, life support systems, etc.

Within the framework of the anthropocentric paradigm, an extensive set of documents regulating the processes of economic and environmental development was developed, including: the UN General Assembly resolution "Economic development and nature protection", the report on the project of the Club of Rome "Limits of Growth" (1972), the documents of the UN summit "Man and the Environment" (1972), the report of M. Mesarovich and E. Pestel "Humanity at a turning point" (1974), etc. The result was the problem of stopping exponential economic growth, which was formulated for the first time on a global scale, and the need to move to qualitative growth that takes into account the parameters of global dynamic balance.

The documents of the UN Assembly in Nairobi (Kenya) in 1982 recorded unsatisfactory results in the implementation of the global principles of sustainable development. The summit participants came to the conclusion that the main causes of environmental problems are rooted in the socio-economic organization of society, thus leading to the transition to a new biosphere-centric paradigm.

The biosphere-centric paradigm is associated with the preservation and revival of the biosphere as the natural basis of all life, stability and natural evolution for the further development of mankind. The formulation of a new development paradigm requires a gradual integration into a single self-organizing system of environmental, economic and social spheres of activity. Figure 2 shows the general relationship between the process of human life and its environmental component. Based on the identified dependencies, sustainable development is characterized by biosphere compatibility, economic efficiency and social justice with a general reduction in the anthropogenic load on the biosphere. The latter, from this point of view, should be perceived as the basis, the foundation of life, and not just a source of resources, its preservation should be subordinated to the functioning of socio-economic systems.

In accordance with the biosphere approach, sustainable development is a purposeful anthropogenic change in the environment and social situation that helps society overcome the limitations of the biosphere conditions of its existence. In the Urban Planning Code of the Russian Federation, the concept of sustainable development of territories is understood as ensuring the safety and favorable conditions for human life, limiting the negative impact of economic and other activities on the environment, and ensuring the protection and rational use of natural resources in the interests of present and future generations.

Representatives of the ecological and economic approach interpret sustainable development as development in which the impact on the environment remains within the economic capacity of the biosphere, the natural basis for the reproduction of human life is not destroyed. Of particular importance is the preservation of the ability to meet the needs, both today and in the future, the growth of well-being, but it is necessary to change the attitude to the exploitation of resources, technological improvement, the direction of investment, and the quality of management. Thus, the sustainable development of society is characterized not by physical, but by qualitative growth.

Theoretical developments within the framework of the biosphere-centric paradigm served as the basis for the development of a new set of documents regulating the processes of economic and environmental development on a global scale. The new paradigm initiated a series of institutional reforms (the UN International Commission on Environment and Development was established in 1983), environmental ministries and departments were formed at the level of national states, etc.)

The UN International Conference on Environment and Development in Rio de Janeiro (1992) proclaimed the transition to a "new era of economic development that is safe for the environment". At the conference, it was noted that in order to achieve sustainable development of human society, it is necessary to ensure a balance of interests between the economic, environmental and social components. The contradictions of socio-ecological and economic development highlighted by the conference became the basis for the transition to a new noosphere paradigm.

A person, as a carrier of new knowledge, can transform the biosphere through the use of natural, human and physical capital for the transition of the life support system to a new quality. The noosphere paradigm is based on V. I. Vernadsky's teaching about the noosphere (the sphere of reason) and consists in the following: a person, having developed a scientific thought in the social sphere, creates a new geological force in the biosphere. The term "noosphere" was used by V. I. Vernadsky in several meanings: as the state of the planet, when man is the main transforming geological force; as the sphere of activation of scientific thought; as the main factor of qualitative transformation of the biosphere. Under the influence of scientific thought and human labor, the biosphere is gradually moving into a new state - the noosphere. This is a natural process that manifests itself as a Law of Nature.

In his work "Scientific Thought as a planetary phenomenon", V. I. Vernadsky pointed out some conditions for the transition to the noosphere, among them: a well-thought-out system of education and education and the rise of the welfare of workers; a prudent transformation of the Earth's nature so that it is able to meet the material, aesthetic and spiritual needs of an increasing population; an increase not only in the rate of development, but also the expansion of the covered space without losing the speed of development.

"Recently, globalization and the integration of national innovation processes are features of the innovative model of economic growth of the leading countries of the world economy, due to the complexity of ensuring technological breakthroughs that guarantee the conquest of new world markets."

To create a noospheric future requires not only a common vision of the problem, but also scientific tools 
of construction, design and management, based on the general laws of Nature and, above all, on the noospheric law of preserving the development of Life as a cosmoplanetary phenomenon. Within the framework of the noosphere paradigm, the following is revealed.

First, sustainable development as an anti-entropy process is a real alternative to the catastrophic course of events; it is an effective way to prevent, mitigate and overcome global crises and catastrophes generated by the modern "risk society". Sustainable development involves the creation of a system of global governance of a globalizing society in order to ensure security and peace in the world.

Secondly, sustainable development as a dialectical process expresses the harmony of opposites: stability and dynamism, persistence and variability. The Earth's biosphere and humanity itself must be preserved. Human civilization and the value consciousness of society must change.

Third, sustainable development as an evolutionary process coincides with the advent of the noosphere, i.e., a sphere of interaction between society and nature, when prudent human activity will become a key factor in the creative evolution of the world. Sustainable development as a noospheric process is a real alternative to the lawlessness of material enrichment and exploitation of natural resources inspired by the" consumer society".

\section{Results and discussions}

Ideas about the content and factors of sustainable development changed in accordance with changes in the content of objective and subjective prerequisites. The first is the change in the dynamics of economic growth indicators and its consequences. The XX century is characterized by the intensification of the processes of urbanization, which led to the search for intensive technologies for the use of natural resources and to an increase in the level of environmental pollution, which created the prerequisites for a global environmental crisis. A significant contribution to the formation of the paradigm of sustainable development was made by a group of scientists - representatives of various scientific fields, who first met in Rome in 1968 and received the name of the"Club of Rome". Since 1968, they have prepared a series of reports under the general title "The Difficulties of humanity", which present forecasts constructed using mathematical models and computer technology, which marked the beginning of global modeling. At the same time, at the first stage of the development of ideas about the sustainable development of society, there were no deep theoretical and methodological approaches to solving this problem. Declarative provisions aimed at the general public with the aim of changing the value system of politicians, entrepreneurs, and the population prevailed. However, the significance of the program documents of the Club of Rome was determined primarily by the fact that they paved the way for research in this area.

The second stage of the development of ideas about sustainable development (the $90 \mathrm{~s}$ of the twentieth century - the beginning of the twenty - first century) is associated with the formation of the conceptual apparatus of the concept. At the same time, the researchers solved a number of key categories, including the category of "sustainable development", "balance and equilibrium development", etc. Some researchers consider the stability of the system only in relation to its development, while others argue that the very words "sustainable" and "development" contradict each other, that development in principle cannot be sustainable, "which should be abandoned: either from development, or from sustainability".

"Sustainable development can be a source of opportunity, innovation, and even competitive advantage."

The conducted research of this category allowed us to conclude that development is a form of realization of the contradiction between the factors of stability and instability. At the same time, stability is interpreted as a property of the economic system that ensures the preservation of its attribute features. Insignificant changes in the components of this system can be interpreted as an evolutionary type of development. If the economic system is dominated by properties that contradict the attributive properties, the economic system is reincarnated (a revolutionary type of development). Bifurcation shifts are the result of fluctuations (changes in the factors of the external and internal environment).

\section{Conclusion}

The selected theoretical developments within the framework of the noosphere paradigm became the basis for the development of a set of documents regulating the processes of economic, environmental and social development: M.Strong's report, Resolutions of the World Conference on Human Rights (Vienna, 1993), the UN International Conference on Population and Development (Cairo, 1994), the World Summit for Social Development (Copenhagen, 1995), the IV World Conference on Women's Rights (Beijing, 1995), the World Summit on Food Security (Rome, 1996), the UN Conference on Human Settlements (Istanbul, 1996), the Kyoto Summit on Global Warming (Japan, 1997), etc. The conceptual foundations of sustainable ecological and economic development are filled with new content over time, and the range of issues that are expected to be resolved in the process of its implementation is expanding. United Nations Conference on Sustainable Development in 2012 (Rio de Janeiro) confirmed that the current capitalist path of development is a dead-end path and that the world civilization is developing incorrectly. It was stated that the eradication of poverty, the rejection of irrational and the promotion of rational consumption and production patterns, and the protection and rational use of natural resources as the basis for economic and social development were the main objectives of sustainable development.

"The degree of stability and time lags of transitions are determined by the state of the institutional 
environment and the effectiveness of management actions."

Despite the documents adopted in the world practice, the current state of the global socio-ecological and economic system is characterized as unstable due to the aggravation of internal contradictions that create conditions for its possible death or transition to a new qualitative state:

1. In the ecological subsystem, the anthropogenic impact of humanity on the environment has exceeded the permissible limits, and the active destruction of the biosphere continues under the influence of mutually dependent processes: economic growth - population growth - resource consumption growth - environmental destruction - the decay of the human genome.

2. The social subsystem is dominated by the philosophy of anthropocentrism.

The ideology of environmental protection is in its infancy. National, group interests dominate over universal interests. Dynamic population growth in countries with low levels of development leads to a widening gap in the standard of living, the growth of the number of poor segments of the population is accompanied by an increase in morbidity, etc.

3. The economic subsystem is dominated by the economic goals of development (profit, enrichment), the extensive path of development prevails, there are no economic criteria indicating the transition of the limits of permissible impact on the environment.

The identified contradictions require further development of the theoretical and methodological basis of the noosphere concept of sustainable development and pose the scientific community with the task of solving the problems of socio-ecological and economic development of society in a comprehensive manner.

\section{References}

1. N. Georgescu-Rogen, Energy and Economic Myths: Institutional and Analytical Economic Essays (New York: Pergamon Press, 1976, 380)

2. J.M. Hartwick, Intergenerational capital and investing rent from exhaustible resources, American Economic Review, 67 (5), 972-974 (1977)

3. R.M. Solow, Intergenerational justice and exhaustible resources, Review of economic research, Op. Iss., 24-45 (1974)

4. E.V. Tretyakova, Evolution of the methodology of research and evaluation of sustainable development of socio-economic systems, 25 (5), 756-759 (2013)

5. V.I. Vernadsky, Scientific thought as a planetary phenomenon (Moscow: Nauka, 1991, 272)

6. World Conference on Human Rights [Electronic resource], Vienna (Austria) (14-25 June 1993) Available

at: http://www.ohchr.org/RU/AboutUs/Pages/Vienna WC.aspx

7. Town-planning Code of the Russian Federation [Electronic resource], 190-FZ (29 December
2004) (as amended 28 December 2013, 418-FZ)

Available

at:

http://www.consultant.ru/popular/gskrf/

8. World Summit Declaration on Food Security [Electronic resource] Available at: http://www.un.org/ru/documents/decl_conv/decla rations/pdf/summit2009_declaration. $\overline{p d f}$

9. Report of the International Conference on Population and Development [Electronic resource] Available at: http://www.unfpa.org/sites/default/files/pubpdf/icpd_rus.pdf

10. Kyoto Summit on Global Warming [Electronic resource] Available at: http://files.schoolcollection.edu.ru/dlrstore/f8215646-c95a-9368af09-0abe72c6c78c/1012528A.htm

11. UN Conference on Environmental Problems in 1972 [Electronic resource] Available at: https://ru.wikipedia.org/wiki/\%D0\%9A\%D0\%BE $\% \mathrm{D} 0 \% \mathrm{BD} \% \mathrm{D} 1 \% 84 \% \mathrm{D} 0 \% \mathrm{~B} 5 \% \mathrm{D} 1 \% 80 \% \mathrm{D} 0 \% \mathrm{~B}$ $5 \% \mathrm{D} 0 \% \mathrm{BD} \% \mathrm{D} 1 \% 86 \% \mathrm{D} 0 \% \mathrm{~B} 8 \% \mathrm{D} 1 \% 8 \mathrm{~F} \% \mathrm{D} 0 \%$ $9 \mathrm{E} \% \mathrm{D} 0 \% 9 \mathrm{E} \% \mathrm{D} 0 \% 9 \mathrm{D} \% \mathrm{D} 0 \% \mathrm{BF} \% \mathrm{D} 0 \% \mathrm{BE} \% \mathrm{D}$ $0 \% \mathrm{BF} \% \mathrm{D} 1 \% 80 \% \mathrm{D} 0 \% \mathrm{BE} \% \mathrm{D} 0 \% \mathrm{~B} 1 \% \mathrm{D} 0 \% \mathrm{BB} \%$ D0\%B5\%D0\%BC\%D0\%B0\%D0\%BC_\%D0\%B E\%D0\%BA\%D1\%80\%D1\%83\%D0\%B $6 \%$ D0\% B0\%D1\%8E\%D1\%89\%D0\%B5\%D0\%B9 \%D1 $\% 81 \% \mathrm{D} 1 \% 80 \% \mathrm{D} 0 \% \mathrm{~B} 5 \% \mathrm{D} 0 \% \mathrm{~B} 4 \% \mathrm{D} 1 \% 8 \overline{\mathrm{B}}-197$ $2 \% \mathrm{D} 0 \% \mathrm{~B} 3 \% \mathrm{D} 0 \% \mathrm{BE} \% \mathrm{D} 0 \% \mathrm{~B} 4 \% \mathrm{D} 0 \% \mathrm{~B} 0$

12. United Nations Conference on Sustainable Development "Rio+20" [Electronic resource] Available at: http://www.un.org/ru/ecosoc/about/uncsdrio.shtml

13. Copenhagen Declaration on Social Development [Electronic resource] Available at: http://www.un.org/ru/documents/decl_conv/decla rations/copdecl.shtml

14. Summary of the report "Limits of growth" [Electronic resource] Available at: http://www.russ-yug.ru/article/643/

15. G.S. Rosenberg, S.A. Chernikova, G.P. Krasnoshchekova, Yu.M. Krylova, D.B. Gelashvili, Myths and reality of "sustainable development", Problems of forecasting, 2, 130154 (2009)

16. M.Yu. Osipova, Theory and methodology of research of sustainable development of socioeconomic systems, Bulletin of the PNRPU, Socio-economic sciences, 4 (25), 81-88 (2014)

17. S.M. Pshikhachev, Paradigm of sustainable development of the agrarian sphere, Economic Bulletin of the Rostov State University, 3 (1), 114-127 (2005)

18. Resolutions of the 37th session (1982-1983) [Electronic resource] Available at: http://www.un.org/ru/ga/37/docs/37res.shtml

19. UN General Assembly Resolution "Economic Development and Nature Protection" [Electronic resource $]$ Available at: http://www.un.org/ru/ga/17/docs/17res.shtml 
20. The Club of Rome and its inhabitants [Electronic resource] Available at: http://www.val-s.narod.ru/rc-istorya.htm

21. Rio Declaration on Environment and Development [Electronic resource] Available at: http://www.un.org/ru/documents/decl_conv/decla rations/riodecl.shtml

22. Istanbul Declaration on Human Settlements [Electronic resource] Available at: http://www.un.org/ru/documents/decl_conv/decla rations/habdecl.shtml

23. A.P. Fedotov, Planet Earth, humanity, economy, Economist, 11, 43-56 (1995)

24. The Fourth World Conference on the status of Women [Electronic resource] Available at: http://www.un.org/ru/events/pastevents/women_c onf_beijing_1995.shtml

25. Environmental crisis, ways out of the environmental crisis, International cooperation to overcome the environmental crisis [Electronic resource] Available at: http://www.soullife.info/kurs-lektsij-podistsipline-ekologiya/308-jekologicheskij-krizisputi-vyhoda-iz.html

26. V.V. Shlychkov, A.S. Khasanova, I.K. Kiyamov, S.M. Kulish, V.R. Nestulaeva, Practical management: theoretical and methodological approaches and Russian practice of state and municipal management, European Research Studies Journal, 20 (2B), 200-223 (2017)

27. A. Khasanova, E. Dotsenko, N. Ezdina, M. Khasanov, The multidimensional impact of ecoinnovations (sustainable goods) as a form of development of the innovative potential of the region, E3S Web of Conferences, 220, 01004 (2020)

28. E. Dotsenko, S. Mudrova, N. Ezdina Zero Waste Technologies and Solution of Economic and Environmental Problems of Sustainable Development E3S Web of Conferences 105, 02008 (2019) 